\title{
Study on Electrokinetic Remediation of Pb-contaminated Saturated Sand
}

\author{
Gang $\mathrm{Li}^{1}$, Yu Li ${ }^{2}$, Jinli Zhang, ${ }^{3, *}$ and Jia Liu ${ }^{4}$ \\ ${ }^{1}$ Shaanxi Key Laboratory of Safety and Durability of Concrete Structures, Xijing University, Xi'an, \\ Shaanxi 710123, China; \\ ${ }^{2}$ School of Management Engineering, Dalian University of Science and Technology, Dalian Liaoning \\ 116052, China; \\ ${ }^{3}$ State Key Laboratory of Coastal and Offshore Engineering, Dalian University of Technology, Dalian, \\ Liaoning 116024, China; \\ ${ }^{4}$ School of Geological Engineering and Geomatics, Chang'an University, Xi'an, Shaanxi 710054, \\ China. \\ *E-mail: jlzhang@dlut.edu.cn
}

doi: $10.20964 / 2020.02 .40$

Received: 6 October 2019/ Accepted: 5 December 2019 / Published: 31 December 2019

Electrokinetic remediation is a green remediation technology for contaminated soil, and it has the advantages of low cost, easy operation, minimal secondary pollution, and broad application prospects. In this study, electrokinetic remediation and combined electrokinetic remediation experiments were carried out on $\mathrm{Pb}(\mathrm{II})$-contaminated saturated sand. The distributions of current density $\left(I_{\mathrm{d}}\right)$, potential gradient $\left(U_{\mathrm{g}}\right), \mathrm{pH}$ value, and $\mathrm{Pb}$ (II) were analyzed, and the energy consumption $\left(E_{\mathrm{c}}\right)$ of the electrokinetic remediation was discussed. The results showed that the removal rate $\left(E_{\mathrm{r}}\right)$ of $\mathrm{Pb}$ (II) reached $98.37 \%$ after $24 \mathrm{~h}$ when the $0.2 \mathrm{~mol} / \mathrm{L}$ of $\mathrm{KCl}$ was the electrolyte and the $U_{\mathrm{g}}$ was $3 \mathrm{~V} / \mathrm{cm}$. With the electrokinetic remediation method, the coated titanium electrode had a significant advantage over the graphite electrode. The electrolysis efficiency increased as the concentration of $\mathrm{KCl}$ electrolyte increased. In addition, the conductivity of the $\mathrm{KNO}_{3}$ electrolyte was higher than that of the $\mathrm{KCl}$ electrolyte. During the electrokinetic remediation process, acidification/alkalinization and a focusing effect might occur in the sand samples, which could affect the efficiency of the remediation. The acidification/alkalinization issue could be effectively addressed by adopting the combined electrokinetic remediation method using citric acid or sodium citrate as a buffer solution. The polarity exchange method had little influence on the electrokinetic remediation.

Keywords: electrokinetic remediation; lead contamination; saturated sand; electrolyte; buffer solution 
(C) 2020 The Authors. Published by ESG (www.electrochemsci.org). This article is an open access article distributed under the terms and conditions of the Creative Commons Attribution license (http://creativecommons.org/licenses/by/4.0/). 